\title{
CARBON DIOXIDE CONTROL SYSTEM FOR A MARS SPACE SUIT LIFE SUPPORT SYSTEM
}

\author{
Gökhan Alptekin, Ambalavanan Jayaraman, Robert Copeland and Amanda Parker \\ TDA Research Inc., Wheat Ridge, CO - 80033 \\ and \\ Heather L. Paul \\ NASA Johnson Space Center, Houston TX
}

\begin{abstract}
Carbon dioxide $\left(\mathrm{CO}_{2}\right)$ control during Extravehicular Activities (EVAs) on Mars will be challenging. Lithium hydroxide $(\mathrm{LiOH})$ canisters have impractical logistics penalties, and regenerable metal oxide (MetOx) canisters weigh too much. Cycling bed systems and permeable membranes that are regenerable in space vacuum cannot vent on Mars due to the high partial pressure of $\mathrm{CO}_{2}$ in the atmosphere. Although sweep gas regeneration is under investigation, the feasibility, logistics penalties, and failure modes associated with this technique have not been fully determined.
\end{abstract}

TDA Research, Inc. is developing a durable, high-capacity regenerable adsorbent that can remove $\mathrm{CO}_{2}$ from the space suit ventilation loop. The system design allows sorbent regeneration at or above 6 torr, eliminating the potential for Martian atmosphere to leak into the regeneration bed and into the ventilation loop. Regeneration during EVA eliminates the consumable requirement related to the use of $\mathrm{LiOH}$ canisters and the mission duration limitations imposed by MetOx system. The concept minimizes the amount of consumable to be brought from Earth and makes the mission more affordable, while providing great operational flexibility during EVA.

The feasibility of the concept has been demonstrated in a series of bench-scale experiments and a preliminary system analysis. Results indicate that sorbent regeneration can be accomplished by applying a $14^{\circ} \mathrm{C}$ temperature swing, while regenerating at 13 torr (well above the Martian atmospheric pressure), withstanding over 1,000 adsorption/regeneration cycles. This paper presents the latest results from these sorbent and system development efforts. 